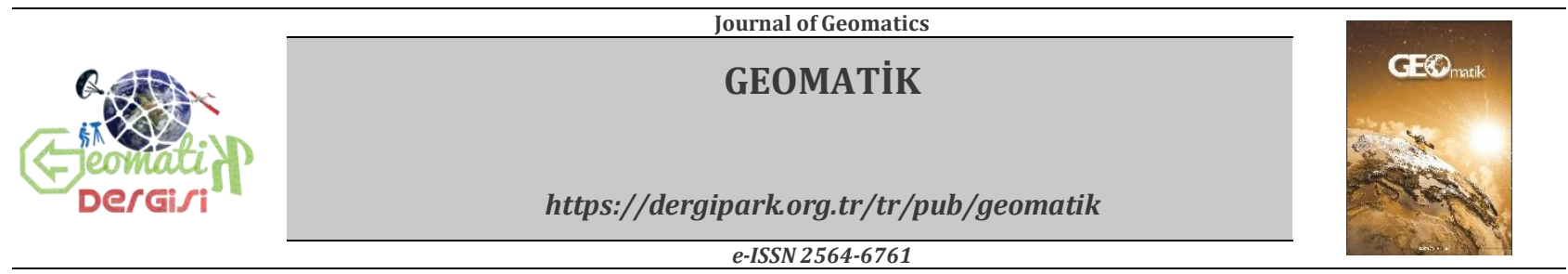

\title{
Farklı GNSS uydu sistemlerinin hassas nokta konumlama (PPP) tekniğinin performansına etkisinin incelenmesi
}

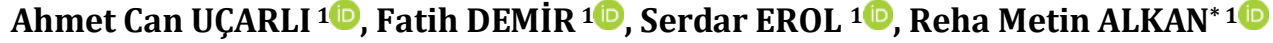 \\ 1 Geomatik Mühendisliği Bölümü, İstanbul Teknik Üniversitesi, İstanbul, Türkiye
}

\author{
Anahtar Kelimeler \\ MultiGNSS \\ Hassas Nokta Konumlama \\ PPP \\ Web-tabanlı Online GNSS \\ Veri Değerlendirme
}

\begin{abstract}
ÖZ
Uydu jeodezisi ile veri işleme ve analizindeki gelişmeler sonucunda herhangi bir referans istasyonunda toplanan verileri kullanmaya gerek duymadan, tek bir GNSS alıcısı ile santimetre doğruluğunda konum belirlemeyi mümkün kılan PPP tekniği geliştirilmiștir. $\mathrm{Bu}$ yöntemde, tek bir alıcı ile toplanan veriler, farklı kuruluşlarca üretilen hassas uydu yörünge ve saat bilgileri ile birlikte değerlendirilerek, statik veya kinematik olarak yüksek doğrulukta konum belirlenebilmektedir. PPP tekniği ile koordinatların belirlenebilmesi için pek çok yaklaşım olmakla birlikte, son zamanlarda web-tabanlı online veri değerlendirme servisleri tüm dünyada bașarıyla yaygın olarak kullanılmaya bașlanmıştır. Öte yandan GPS ile bașlayan uydu-bazlı konum belirleme çalışmaları, izleyen zamanda GLONASS, Galileo ve BeiDou uydularının da eklenmesiyle birlikte GNSS olarak adlandırılan tümleşik bir konum belirleme sisteminin meydana gelmesini sağlamıştır. Bu çalışma kapsamında İTÜ Ayazağa Kampüsünde, farklı uydu gözlem özelliklerine sahip noktalar tesis edilmiş ve çoklu-GNSS'in statik PPP nokta konum doğruluğuna etkisi incelenmiştir. Çalışmadan elde edilen sonuçlar, PPP tekniği ile elde edilen doğrulukların ölçme yapılan noktadaki fiziki koşullara, uydu sayısına ve uyduların geometrisine bağlı olarak anlamlı șekilde değiștiğini, birden fazla uydu sistemi ile yapılan ölçmelerin de özellikle uydu görünürlüğü kısıtlı noktalarda yapılan ölçmelerin sonuçları üzerinde anlamlı düzeyde iyileştirici bir rol oynadığını ortaya koymuştur.
\end{abstract}

\section{Investigation of the effect of different GNSS satellite systems on the performance of the precise point positioning (PPP) technique}

\author{
Keywords \\ MultiGNSS \\ Precise Point Positioning \\ PPP \\ Web-based Online GNSS \\ Data Processing
}

\begin{abstract}
As a result of developments in satellite geodesy and data processing and analysis, the PPP technique has been developed that enables centimeter-accurate positioning with a single GNSS receiver, without the need to use data collected from any reference station. In this method, the data collected with a single receiver is processed together with the precise satellite orbit and clock information produced by different organizations, and the position can be determined as static or kinematic with high accuracy. Although the re are many approaches for determining the coordinates with the PPP technique, recently webbased online data processing services have been successfully used all over the world. On the other hand, satellite-based positioning studies that started with GPS, with the addition of GLONASS, Galileo and BeiDou satellites in the following time, led to the formation of an integrated positioning system called GNSS. Within this study, points with different satellite observation characteristics were established in ITU Ayazağa Campus and the effect of multi-GNSS on static PPP accuracy was examined. The results obtained from the study show that the accuracies obtained with the PPP technique vary significantly depending on the physical conditions at the point where the measurement is made, the number of satellites and the geometry of the satellites. Additionally, the measurements made with more than a single satellite system showed a significant improvement role in the results of the measurements made especially in restricted conditions with respect to satellite visibility.
\end{abstract}




\section{GíRiş}

1 Ocak 1994 tarihinde resmi olarak faaliyete başlayan International GNSS Service (IGS), o tarihten bu yana yüksek kalitede pek çok Global Navigation Satellite System (GNSS) ürününü (farklı gecikme sürelerinde ve doğruluklarında üretilen hassas uydu yörünge ve saat ürünleri, yer dönme parametreleri, IGS istasyonlarının koordinatları ve hızları, sabit istasyonlara ilişkin saat bilgilerini) bilim dünyasının kullanımına sunmuştur (Kahveci ve Yıldız, 2012). Bu ürünler, farklı amaçları yerine getirmek üzere yapılan bilimsel araştırmalarda ve mühendislik projeleri ile jeodezik ve jeofizik amaçlı pek çok GNSS uygulamasında yaygın olarak kullanılmakla birlikte, uydu-bazlı konum belirlemede yeni algoritmaların ve tekniklerin ortaya çıkmasını da sağlamıştır. Bunların içerisinde en yaygın olarak kullanılanı, Hassas Nokta Konumlama (Precise Point Positioning-PPP) olarak adlandırılan tekniktir. PPP her ne kadar 1970'li yıllarda R.J. Anderle tarafından önerilmiş olsa da, IGS ürünlerinin kalitesi ve doğruluğundaki gelişmelere bağlı olarak günümüzün standart konum belirleme tekniği haline gelmiş ve tüm dünyada yaygın olarak kullanılmaya bașlanılmıștır. Söz konusu bu yöntem sadece GPS (Global Positioning System) uydularından değil, diğer uydu sistemlerinden de alınan verilerin birlikte değerlendirildiği çoklu-GNSS (multi-GNSS) PPP konseptine dönüşmüş, böylelikle çok daha fazla uydu ile daha zorlu ölçme koşullarında daha iyi performansla konum belirlemek mümkün hale gelmiştir. PPP, pek çok temel ölçme uygulamasında, heyelan izleme çalışmalarında, deprem araştırmalarında, erken uyarı sistemlerinin oluşturulmasında, buzul hareketlerinin izlenmesinde, hassas tarımda, yapı sağlı̆̆ izlemede, deniz ölçmelerinde, fotogrametrik çalışmalarda ve İHA ölçmelerinde yaygın olarak kullanılmaktadır.

$\mathrm{Bu}$ çalışmada, çoklu-GNSS Hassas Nokta Konumlama (PPP) tekniğinin statik uygulamalardaki konum doğruluğu araştırılmıştır. Bu amaçla, orman alanı, su kıyısı, yerleşim alanı, açık alan gibi farklı fiziki koşullara ve yapay/doğal çevresel engellere sahip noktalarda ölçmeler yapılmış, farklı değerlendirme stratejileriyle toplanan veriler değerlendirilerek, çoklu-GNSS'in statik PPP nokta konum doğruluğuna etkisi araştırılmıştır.

\section{HASSAS NOKTA KONUMLAMA TEKNIĞİ (PPP)}

Günümüzde konum bilgisi teknolojinin gelişimine de bağlı olarak gerek mühendislik uygulamaları gerekse gündelik hayatta yaşamın önemli bir parçası haline gelmiştir. Bu konuda en sık başvurulan yöntem hiç kuşkusuz uydu-bazlı konum belirleme sistemleridir. $\mathrm{Bu}$ alanda yapılan ilk çalışmalar 1994 yılında global olarak kullanıma sunulan Amerika Birleşik Devletleri Savunma Bakanlığı'nca geliştirilen NAVSTAR-GPS (NAVigation Satellite Timing And Ranging-Global Positioning System) ya da yaygın olarak kullanılan ve bilinen biçimiyle GPS ile başlamıştır. Halen (18 Temmuz 2020 itibariyle) mevcut 31 uydusu ile GPS (30’u aktif), çok farklı alanlarda tüm dünyada en çok kullanılan uydu-bazlı konum belirleme sistemidir. İzleyen zaman içerisinde Rusya'nın GLObal'naya NAvigatsionnaya Sputnikovaya Sistema (GLONASS) sistemi geliştirilmiş, bir dizi süreçten sonra 2011 yılında tekrar tüm dünyada kullanılır hale gelmiştir. GLONASS sisteminde toplam 24 uydu olup, 23'ü fiili olarak çalışmaktadır. Bu iki sistem uzun süre kullanılmış, diğer yandan da Avrupa Birliğine ait Galileo ile Çin Halk Cumhuriyeti tarafından işletilen BeiDou Navigation Satellite System (BDS) sistemleri de devreye girmiştir. Bu uydu sistemlerinden Galileo 2016'da kullanıma başlanmış olup, halen 22'si aktif olmak üzere 24 uyduya sahiptir. BDS sistemi ise 2018'den beri tamamen kullanılmaya bașlanmıș olup, toplam 49 uyduya sahiptir (şu anda 44'ü aktif). Tüm bu uydu sistemleri Global Navigation Satellite System (GNSS) olarak tanımlanan, 100'ün üzerinde uydu ile tüm dünyaya hizmet veren tümleşik bir konum belirleme sistemini oluşturmuşlardır (Int Kyn. 1). GNSS ile uygulanan ölçme yöntemine ve kullanılan donanıma bağlı olarak metreler mertebesinden, santimetre-milimetreye varan doğruluk aralığında konum (hız ve zaman ile birlikte) belirlenebilmektedir.

Günümüzde Hassas Nokta Konumlama (Precise Point Positioning-PPP) adı verilen teknik, tüm dünyada pek çok farklı uygulamada yaygın bir şekilde kullanılmaktadır. PPP ile tek veya çokfrekanslı tek bir GNSS alıcısıyla toplanan kod ve taşıyıcı faz ölçüleri ile birlikte başta International GNSS Service (IGS) olmak üzere, GFZ (German Research Center for Geoscience), JPL (Jet Propulsion Laboratory), Center for Orbit Determination in Europe (CODE) gibi analiz merkezlerinin kullanıma sunduğu hassas uydu yörünge, saat düzeltmeleri ve kod-faz sapma değerleri de kullanılarak yapılan değerlendirmeler sonucunda, statik ve dinamik olarak cm-dm doğruluğunda, global bir koordinat sisteminde 3D konum belirlenebilmektedir. Ancak yüksek doğruluk gereksinimi için ölçmelere etki eden hataların modellenmesi veya düzeltmelerin getirilmesi gereklidir. Bunlar, iyonosfer ve troposferden kaynaklanan hatalar, uydu/alıcı anteni faz merkezi kayıklıkları, faz dönmesi, kutup ve katı yeryuvarı gel-giti, okyanus yüklemesi, ve Sagnac etkilerini içeren rölativistik etkiler, yeryuvarı dönme parametreleri, alıcı ve uydu kod ve faz sapma değerleridir (Héroux and Kouba, 2001; Nie et al., 2020).

Yöntem ilk olarak Anderle (1976) tarafindan uygulanmış olmakla birlikte, günümüzdeki anlamda ilk kez Zumberge ve arkadaşları tarafından 1997 yılında gerçekleştirilen çalışmalarıyla birlikte yaygın kullanıma başlanmıştır (Zumberge et al., 1997). Bu çalışmada çift frekanslı GPS alıcıları ile toplanan pseudorange ve taşıyıcı faz ölçmeleri kullanılmış ve PPP tekniği ile oldukça yüksek doğrulukta konum belirlenebileceği ortaya konulmuştur. 0 zamandan bu yana PPP tekniği tüm dünyada birçok farklı 
bilimsel ve pratik uygulamada başarıyla kullanılmıștır (Zumberge et al., 1997; Héroux and Kouba, 2001; Rizos et al., 2012; Choy et al., 2017; Bahadur and Nohutcu, 2019; Dawidowicz, 2020; Facio and Berber, 2020; Kiliszek and Kroszczyński, 2020; Liu et al., 2020).

PPP tekniği başlangıçta sadece GPS gözlemlerine uygulanmış olsa da, diğer uydu sistemleri için hassas ürünlerin üretilip, kullanıma sunulmasiyla birlikte GLONASS, Galileo ve BeiDou uydularının da kullanıldığı çoklu-GNSS (multi-GNSS) PPP konsepti ortaya çıkmıștır. Bu yaklașım, özellikle yüksek katlı binaların yer aldığı yoğun yerleşim yerlerinde, ormanlık alanlarda, derin açık maden işletmelerinde, vadilerde ve buna benzer uydu gözlemleri açısından görüş açısının kısıtlı olduğu ortamlarda daha fazla uydudan veri alınmasını sağlayarak, yüksek doğruluk ve güvenirlikle konum belirlemeyi mümkün kılmaktadır. Ayrıca tek bir uydu sistemine bağımlılı̆ı da ortadan kaldırmaktadır. Ancak GPS gözlemleri kullanılmadan diğer uydularla yapılan çözümlerde oldukça düşük performans elde edilmekte olup, GPS verileri PPP için hala en baskın ve vazgeçilmez uydu sistemi olma özelliğini korumaktadır (Bahadur ve Nohutcu, 2019). Bu yöntemde; kullanılan alıcı tipine (düșük maliyetli OEM tipi, jeodezik vb), kullanılan ölçü türüne (kod/faz), frekans sayısına (tek, çift ve çoklufrekans), gözlem yapılan uydu sayısına ve türüne (GPS, GLONASS, Galileo, BDS veya Multi-GNSS) ve ölçme süresine bağlı olarak statik yöntemle $\mathrm{mm}-\mathrm{cm}$ mertebesinde; kinematik yöntemle de $\mathrm{cm}$-dm mertebesinde doğruluğa ulaşılabilmektedir. $\mathrm{Bu}$ çalışmada en az iki veya daha fazla uydu sistemi ile yapılan konum belirleme işlemi, çoklu-GNSS PPP olarak kabul edilmiștir.

Konum belirleyebilmek için kullanıcıların tek bir GNSS alıcısı ile veri toplamalarının yeterli olması operasyon serbestisi sağlayarak yöntemi kolay uygulanabilir kılmakta ve ölçme maliyetini de ciddi şekilde düşürmektedir. Bu yöntemle, homojen doğrulukla küresel bir referans sisteminde konum belirlenebilmektedir. Bu önemli avantajlara karşın yöntemin bazı eksiklikleri de bulunmaktadır. Bunların en önemlisi cm mertebesinde bir doğruluğa erişebilmek için 20-30 dakika veya üzeri bir yakınsama süresine (convergence time) gereksinim duyulmasıdır. Bu durum yöntemin gerçek-zamanlı uygulamalarda kullanımını da zorlaștırmakta, hatta kısitlamaktadır. Literatürde GPS uydu sistemlerine diğer Küresel Konum Belirleme sistemlerinin eklenmesinin, yakınsama süresinin azaltılmasına katkı sağladığı ifade edilmektedir. Tamsayı belirsizliğinin sabitlenerek yapılan PPP çözümleri, bu yakınsama süresinin kısalmasına katkı sağlamaktadır (Wang, 2014). Ayrıca bu çözüm yöntemi float tamsayı belirsizliği çözümüne göre çok daha yüksek doğruluk ve güvenirlikte çözüm sağlamaktadır (Bisnath and Collins, 2012).

Her bir uydu navigasyon sisteminin datumu, zaman sistemi ve sinyal yapısı birbirinden farklı olduğu için, çoklu-GNNS sisteminde bu durumun çözümde dikkate alınması gerekmektedir. Ancak, IGS Multi-GNSS Experiment (MGEX) projesi kapsamında bütün uydu yörünge bilgileri ve saat hataları aynı datumda ve zaman sisteminde belirlendiği için, çoklu-GNSS çözümlerinde bu ürünlerin kullanılması datum ve zaman sistemi problemlerini ortadan kaldıracaktır. Çoklu-GNSS PPP modeli için kod ve faz gözlem eşitlikleri aşağıda verilmiștir (Cai et al., 2015):

$$
\begin{aligned}
& P_{i, r}^{S}=\rho_{r}^{s}+c \Delta t_{r}^{s}-c \Delta T^{s}+T_{r}^{s}+I_{i, r}^{s}+O^{s}+\varepsilon\left(P_{i, r}^{s}\right) \\
& \mathrm{L}_{\mathrm{i}, \mathrm{r}}^{\mathrm{s}}=\rho_{\mathrm{r}}^{\mathrm{s}}+c \Delta \mathrm{t}_{\mathrm{r}}^{\mathrm{s}}-c \Delta \mathrm{T}^{\mathrm{s}}+\mathrm{T}_{\mathrm{r}}^{\mathrm{s}}-\mathrm{I}_{\mathrm{i}, \mathrm{r}}^{\mathrm{s}}+\lambda_{\mathrm{i}}^{s} \mathrm{~N}_{\mathrm{i}}^{s}+0^{s}+\varepsilon\left(\mathrm{L}_{\mathrm{i}, \mathrm{r}}^{\mathrm{s}}\right)
\end{aligned}
$$

Eşitliklerdeki $r$ ve $i$ sırasıyla alıcıyı ve sinyal frekansını, $s$ ise GNSS türünü (G:GPS, R:GLONASS, E:Galileo ve C:BeiDou) göstermektedir. Ayrıca, $P_{i, r}^{S}$ kod ölçüsünü (m), $L_{i, r}^{S}$ faz ölçüsünü (m), $\rho_{r}^{S}$ uydu-alıcı arası geometrik uzunluğu (m), $c$ ışık hızını (m/sn), $\Delta t_{r}^{s}$ alıcı-donanım kod hatasına göre düzenlenmiş alıcl saat hatasını (s), $\Delta T^{s}$ uydu donanım kod hatasına göre düzenlenmiş uydu saat hatasını (s), $T_{r}^{s}$ troposferik gecikmeyi (m), $I_{i, r}^{s}$ ilgili frekanstaki iyonosferik gecikmeyi $(\mathrm{m}), O^{s}$ uydu yörünge hatasını (m), $N_{i}^{s}$ alıcı ve uydu kod ve faz hatalarına göre düzenlenmiş tam sayı belirsizliğini, $\lambda_{i}^{s}$ ilgili frekansın dalga boyunu $(\mathrm{m})$ ve $\varepsilon(\cdot)$ ise çokyolluluk (multipath) hatası dahil diğer modellenemeyen hataları (m) ifade etmektedir. Yukarıdaki eşitliklerdeki uydu yörünge ve saat hatalarını yok etmek için MGEX hassas ürünleri kullanılır. Ayrıca birinci dereceden iyonosferik gecikmeyi yok etmek için her bir sistemdeki frekansları $\left(f_{1}\right.$ ve $\left.f_{2}\right)$ ikili kombinasyonuyla iyonosferden bağımsız kod ve faz gözlem eşitlikleri aşağıdaki formüller yardımıyla oluşturulur.

$$
\begin{aligned}
& P_{I F, r}^{S}=\left(f_{1}^{2} P_{1}^{S}-f_{2}^{2} P_{2}^{S}\right) /\left(f_{1}^{2}-f_{2}^{2}\right) \\
& L_{I F, r}^{S}=\left(f_{1}^{2} L_{1}^{S}-f_{2}^{2} L_{2}^{S}\right) /\left(f_{1}^{2}-f_{2}^{2}\right)
\end{aligned}
$$

Eşitliklerdeki $\quad P_{I F, r}^{S} \quad$ ve $\quad L_{I F, r}^{S}, \quad$ sirasiyla iyonosferden bağımsız kod ve faz ölçülerini, $f_{1}$ ve $f_{2}$ ise taşıyıcı dalga frekanslarını göstermektedir. Böylelikle uydu saat hatası, yörünge hatası ve iyonosferik hatadan arındırılmış GPS, GLONASS, Galileo ve BeiDou sistemleri için kod ve faz gözlemlerinin iyonosferden bağımsız gözlem eşitlikleri aşağıdaki gibi oluşturulmaktadır.

$$
\begin{aligned}
& P_{I F, r}^{G}=\rho_{r}^{G}+c \Delta t_{r}^{G}+T_{r}^{G}+\varepsilon\left(P_{I F, r}^{G}\right) \\
& L_{I F, r}^{G}=\rho_{r}^{G}+c \Delta t_{r}^{G}+T_{r}^{G}+\lambda_{I F}^{G} N_{I F}^{G}+\varepsilon\left(L_{I F, r}^{G}\right) \\
& P_{I F, r}^{R}=\rho_{r}^{R}+c \Delta t_{r}^{G}+c d t_{s y s}^{R}+T_{r}^{R}+\varepsilon\left(P_{I F, r}^{R}\right) \\
& L_{I F, r}^{R}=\rho_{r}^{R}+c \Delta t_{r}^{G}+c d t_{s y s}^{R}+T_{r}^{R}+\lambda_{I F}^{R} N_{I F}^{R}+\varepsilon\left(L_{I F, r}^{R}\right) \\
& P_{I F, r}^{E}=\rho_{r}^{E}+c \Delta t_{r}^{G}+c d t_{s y s}^{E}+T_{r}^{E}+\varepsilon\left(P_{I F, r}^{E}\right)
\end{aligned}
$$


$L_{I F, r}^{E}=\rho_{r}^{E}+c \Delta t_{r}^{G}+c d t_{s y s}^{E}+T_{r}^{E}+\lambda_{I F}^{E} N_{I F}^{E}+\varepsilon\left(L_{I F, r}^{E}\right)$

$P_{I F, r}^{C}=\rho_{r}^{C}+c \Delta t_{r}^{G}+c d t_{s y s}^{C}+T_{r}^{C}+\varepsilon\left(P_{I F, r}^{C}\right)$

$L_{I F, r}^{C}=\rho_{r}^{C}+c \Delta t_{r}^{G}+c d t_{s y s}^{C}+T_{r}^{C}+\lambda_{I F}^{C} N_{I F}^{C}+\varepsilon\left(L_{I F, r}^{C}\right)$

Eşitliklerde, her bir sistem için ayrı alıcı saat hatası belirtmek yerine GPS'e göre olan farkı yansitan sistemler-arası fark parametreleri $\left(c d t_{s y s}^{R}\right.$, $c d t_{\text {sys }}^{E}$ ve $c d t_{\text {sys }}^{C}$ ) modele dâhil edilmiștir.

\section{WEB-TABANLI ONLINE GNSS VERI DEĞERLENDİRME SERVISLERi}

PPP yöntemi ile konum belirleyebilmek için farklı alternatifler bulunmaktadır. Bunlar genel olarak şöyle sıralanabilir:

- Bilimsel (Akademik) Programlar (Bernese, GipsyX vd),

- Ticari Programlar (GrafNav vd),

- In-house Programlar (RTKLib, Net_Diff vd),

- Web-tabanlı Online GNSS Değerlendirme Servisleri (APPS, CSRS-PPP, magicGNSS, Trimble RTX-PP vd).

Bunlardan bilimsel tabanlı olanların kullanılabilmesi için güçlü bir GNSS teorik bilgiye sahip olunması gerekmektedir. Bazıları ücretsiz olmakla birlikte, örneğin en yaygın kullanılanlarından birisi olan Bernese yazılımı için oldukça ciddi miktarda bir lisans ücreti ödenmesi gerekmektedir. Benzer durum ticari programlar için de geçerlidir. In-house programlar ise genellikle bir kurumun kendi imkanları ile yapılmakta olup, kodlayan kullanıcının ihtiyaçlarını ön plana aldığı, buna bağlı olarak da elde edilen sonuçların programı hazırlayanların kurduğu algoritmaya doğrudan bağlı olduğu, çoğunlukla da kullanımı pratik olmayan yazılımlardır (Alkan ve diğ., 2015). Son gruptakilerse, web-tabanlı online değerlendirme servisleri, diğer yaklaşımlardaki pek çok olumsuzlar olmaksızın, oldukça kolay bir şekilde GNSS verilerinin değerlendirilmesine imkân sağlamaktadır. Hemen hemen tümü ücretsiz olan bu servislerin kullanılabilmesi için internet bağlantısı olan bir bilgisayar ile geçerli bir e-posta adresi genellikle yeterli olmaktadır. Temel seviyede GNSS bilgisine sahip bir kullanıcının yapması gereken, sahada topladığı GNSS verilerini servislerin webtabanlı ara yüzlerinden yararlanarak veya eposta/FTP aracılığıyla servise ulaştırmasıdır. Değerlendirme aşamasında ise, veri değerlendirme yöntemi (statik/kinematik), atmosferik hata düzeltme yöntemi, kullanılan antenin tanıtılması ve çözümün hangi koordinat sistemine dayalı olacağı gibi temel bazı bilgilerin girilmesinden ibaret olmaktadır. Servisler verileri aldıktan sonra değerlendirmeye bașlamakta ve toplanan verinin boyutuna, internet hızına ve servisin yoğunluğuna bağlı olarak kısa sayllacak bir süre sonrasında (genellikle dakikalar mertebesinde) sonuçları çeşitli formatlarda göndermektedir. Bu sonuçlar, sadece
PPP koordinatlarını değil, aynı zamanda sonuçların yorumlanmasına imkân sağlayacak ek bilgileri (saat hataları, troposferik toplam zenit gecikmesi, DOPDilution of Precision) grafikler ve tablolarla zenginleștirerek rapor halinde kullanıcılara göndermektedir. Servislerin bazıları sadece GPS verilerini kabul ederken, pek çoğu buna ek olarak diğer uydu sistemlerini de hesaplarına katarak çoklu-GNSS PPP çözümü üretmektedir. Önemli bir kısmı float çözüm ile sonuçları hesaplarken (APPS, CSRS-PPP, magicGNSS gibi), kısıtlı sayıdaki birkaçı da (Trimble RTX-PP gibi) "başlangıç belirsizliği”ni ya da "tamsayı belirsizliği"ni sabitleyerek (PPP with ambiguity resolution - PPP-AR) çözüm vermektedir. Hiç şüphesiz ikinci yaklaşım, yakınsamanın gerçekleşmesi için yeterli ölçme süresi olması halinde float çözüme göre daha yüksek doğruluk sağlamaktadır.

Diğer yandan bu tür servislerin dezavantajları, standart veri değerlendirme seçenekleri dışında kullanıcıya çoğunlukla alternatif sunulmaması veya sınırlı olması, değerlendirme süreci sonunda yapılan hesaplara ilișkin ayrıntılı bilgi verilmemesi, internet hızına bağlı olarak büyük hacimli verilerin yüklenmesi ve/veya sonuçların alınmasındaki gecikmelerdir. Ayrıca Internet bağlantısındaki kesintiler veya yapılan güncellemeler nedeniyle servislere erişilememesi de önemli bir sorun olabilmektedir.

Çalışmanın uygulama kısmında kullanılan online servisler ile ilgili veri değerlendirme yöntemleri, çözüm için kullandıkları ürünler ve genel olarak son kullanıcı deneyimi ile ilgili bilgiler, izleyen kısımlarda verilmektedir.

\subsection{Automatic Precise Positioning Service (APPS)}

Automatic Precise Positioning Service (APPS), NASA Jet Propulsion Laboratory (JPL) tarafindan işletilen web-tabanlı bir GPS değerlendirme servisidir. Servis JPL tarafından üretilen gerçek zamanlı, günlük ve haftalık GPS yörünge ve saat bilgilerini kullanmaktadır. APPS, sadece GPS uydularından alınan çift frekanslı verileri değerlendirerek GIPSY 6.4 bilimsel yazılımı ile statik veya kinematik (kayıtlı kullanıcılar için) yöntemlerle PPP koordinatlarını hesaplamaktadır. RINEX 2, RINEX 2.11 formatlarındaki veriler, servisin web sayfası aracılığıyla kısıtlı seçeneklerle veya eposta/FTP ile gönderilebilmektedir. Değerlendirme aşamasında NASA Jet Propulsion Laboratory tarafından üretilen hassas uydu yörünge ve saat ürünlerinden (real-time, ultra-rapid, rapid ve final) yararlanılmaktadır. En yüksek doğruluklu hassas uydu yörünge ve saat düzeltmeleri haftalık periyodlarda üretilerek yayınlanmakta olup, en yüksek doğruluk için bu sürenin beklenmesi gerekmektedir (Alkan ve diğ., 2017). Gönderilen veriler ITRF14 datumunda hesaplanarak, diğer ek bilgiler ile kullanıcılara gönderilmektedir. APPS-PPP 
değerlendirme servisi ile ilgili güncel bilgiler servisin web sayfasında yer almaktadır (Int Kyn. 2).

\subsection{Canadian Spatial Reference System-Precise Point Positioning (CSRS-PPP)}

CSRS-PPP, Geodetic Survey Division of Natural Resources Canada (NRCan) tarafından işletilen webtabanlı bir GNSS-PPP değerlendirme servisidir. Üyelik sistemi ile çalışan servis ile tek veya çift frekanslı GNSS gözlemleri (GPS ve GLONASS) , statik veya kinematik olarak PPP yöntemi ile değerlendirilmektedir. Servis, 2003 yılından bu yana 3 milyondan fazla GNSS veri setini değerlendirerek tüm dünyadaki kullanıcılara ücretsiz olarak hizmet vermektedir. Kullanıcıların yapması gereken, sahada topladıkları RINEX (max. 300 MB, *.zip, *.gzip, *.gz, *.Z, *.tar, veya *.??O formatlarında) verileri, değerlendirme yöntemi (statik/kinematik), referans sistemi seçimi (NAD83 veya ITRF14) ile gerekirse kıyı bölgesi uygulamaları için okyanus gelgit yükleme dosyalarını yüklemesinden ibarettir.

Servis verileri aldıktan sonra, o zaman itibariyle IGS veya NRCan tarafından üretilen en iyi hassas uydu yörünge ve saat ürünlerini (ultra-rapid, rapid veya final) kullanarak verileri değerlendirmekte ve statik veya kinematik olarak PPP koordinatları hesaplamaktadır. Statik yöntem seçilmişse, düzeltilmiş tek bir ortalama koordinat hesaplanmakta, kinematik yöntemde ise düzeltilmiş bir iz (yörünge) üretilmektedir. Ancak GPS için ölçmeler yapıldıktan sonraki ilk 90 dakika, GLONASS için de 3 saat boyunca çözüm üretilememektedir. Yapılan değerlendirme sonuçları PPP koordinatları ve değerlendirmeye ait ek bilgileri içeren dosyalar halinde kullanıcıya e-posta aracılığıyla iletilir. CSRSPPP değerlendirme servisi hakkında detaylı bilgiler servisin web sayfasında yer almaktadır (Int Kyn. 3).

\section{3. magicGNSS-PPP}

İspanya menşeili GMV Aerospace and Defense Company tarafından geliştirilen magicGNSS değerlendirme servisi, 2008 yılında kullanıma sunulmuștur. Web-tabanlı olarak hizmet veren magicGNSS'in ücretsiz olan e-posta servisi aracılığıyla sadece GPS ve GLONASS verileri değerlendirilebilirken, belirli bir ücret ödenerek kayıt yaptıran kullanıcılar GPS, GLONASS, Galileo, BeiDou ve QZSS uydularından alınan verileri de değerlendirebilmektedir. Statik ve kinematik değerlendirme seçeneklerine sahip servis, IGS ve GMV'nin ürettiği uydu yörünge ve saat ürünlerini kullanarak gönderilen çift frekanslı GNSS verilerini değerlendirmektedir. Servis, RINEX 2.xx ve 3.xx formatındaki GNSS verilerini kabul etmektedir. İşlemin tamamlanmasının ardından PPP koordinatları ve değerlendirme işlemine ait pek çok istatistiksel bilgiyi de içeren rapor ve grafikler, eposta ile kullanıcılara kısa bir süre içerisinde gönderilmektedir. magicGNSS değerlendirme servisi hakkında detaylı bilgiler servisin web sayfasında yer almaktadır (Int Kyn. 4).

\subsection{Trimble CenterPoint RTX Post-processing Service (Trimble RTX-PP)}

Trimble firması tarafından kullanıma sunulan Trimble CenterPoint RTX (Real Time eXtended) Post-processing servisi (Trimble RTX-PP), statik ölçmelerle toplanan verilerin ücretsiz bir şekilde değerlendirilmelerine imkân sağlamaktadır. Servisten limitsiz bir şekilde yararlanmak isteyen kullanıcıların servise kayıt olması ve her yıl kayıtlarını yenilemeleri yeterli olmaktadır. Firmanın kendi alıcı formatı ile RINEX 2.xx ve RINEX 3.xx formatlarındaki verileri kabul eden servis, GNSS (GPS, GLONASS, Galileo, BeiDou ve QZSS) gözlemlerini içeren dosyayı aldıktan sonra değerlendirmeye başlamakta, sonuçları içeren bir PDF dosyasını kullanıcının e-posta adresine kısa bir süre içerisinde göndermektedir. Servis, ITRF sisteminde ve ölçme yapılan epokta hesaplanan koordinatları bașka bir epoğa kaydırma işleminde, ölçmelerin yapıldığı konum için hesaplanmış yıllık tektonik plaka hareket verilerini kullanmaktadır. RTX-PP servisi "başlangıç belirsizliği"ni tamsayılara sabitleyerek, ambiguity fixed çözüm ile noktaların koordinatlarını hesaplamaktadır. $\mathrm{Bu}$ durum yakınsama süresini ciddi şekilde kısaltmaktadır (Doucet et al., 2012). Servis aracilığıyla ulaşlabilecek doğruluk değeri, pek çok faktöre bağlı olarak değişmekle birlikte, en az 1 saatlik verilerin değerlendirilmesi sonucunda yatayda $2 \mathrm{~cm}$ ve daha iyi, düşeyde de $6 \mathrm{~cm}$ ve daha iyi olarak verilmektedir. Servis hakkında daha detaylı bilgiler, servisin ilgili web sayfasında yer almaktadır (Int Kyn. 5).

\section{UYGULAMA}

\subsection{GNSS Ölçmeleri}

Farklı GNSS uydu sistemlerinin Hassas Nokta Konumlama (PPP) tekniğinin doğruluk performansına etkisini belirleyebilmek için, İTÜ Ayazağa Kampüsü içerisinde farklı çevresel ve topografik özelliklere (dolayısıyla farklı uydu gözlem özelliklerine) sahip;

- Açık Alan,

- Orman Alanı,

- Su Kıyısı (Gölet Alanı),

- Yoğun Yerleşim Alanı

olmak üzere 4 farklı bölgede jeodezik noktalar tesis edilmiş, bu noktalarda statik ölçmeler yapılmıştır. Söz konusu bu ölçme bölgelerinin temel özellikleri aşağıda kısaca açıklanmıştır.

Açık Alan: Gökyüzü görüşünün açık olduğu, herhangi bir engel bulunmayan ve uydulardan gelen sinyalleri engelleyici doğal veya yapay objelerin olmadığı alanlardır. Bu kapsamda 3 adet nokta tesis edilmiştir (Açık Alan 1, Açık Alan 2, Açık Alan 3). Tesis edilen noktalardan bazı görüntüler Şekil 1'de verilmiştir. 

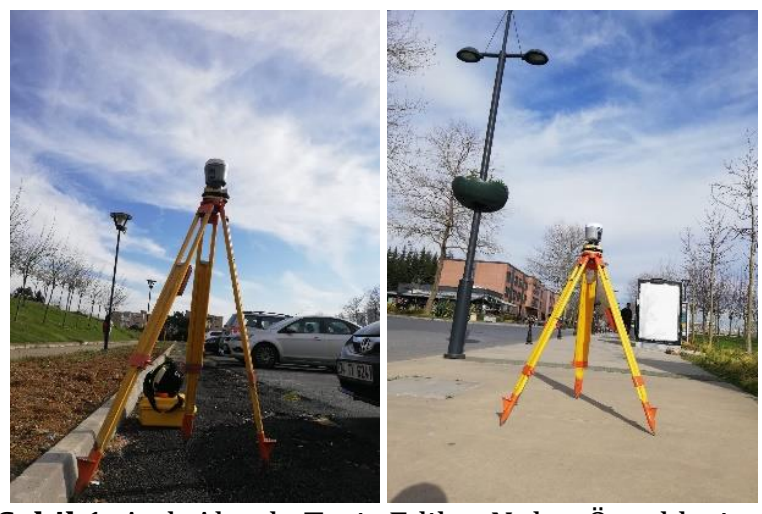

Şekil 1. Açık Alanda Tesis Edilen Nokta Örnekleri

Orman Alanı: Yüksek ağaçların yoğun bir şekilde bulunduğu alanlar olarak tanımlanmıştır. $\mathrm{Bu}$ kapsamda 3 adet nokta tesis edilmiștir (Orman 1, Orman 2, Orman 3). Tesis edilen noktalardan bazı görüntüler Şekil 2'de verilmiştir.
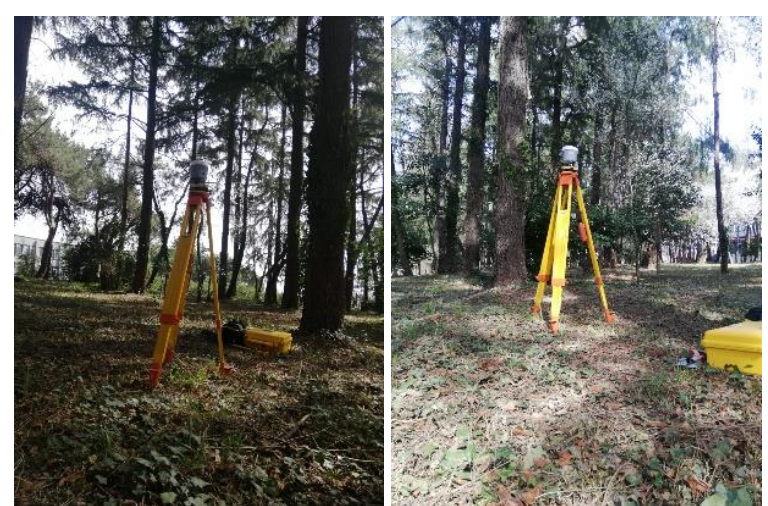

Şekil 2. Ormanlık Alanda Tesis Edilen Nokta Örnekleri

Su Kıyısı (Gölet Alanı): Kampüs içerisinde bulunan göletin hemen çevresindeki alan olarak tanımlanmıştır. Bu kapsamda 3 adet nokta tesis edilmiştir (Gölet 1, Gölet 2, Gölet 3). Tesis edilen noktalardan bazı görüntüler Şekil 3'de verilmiștir.
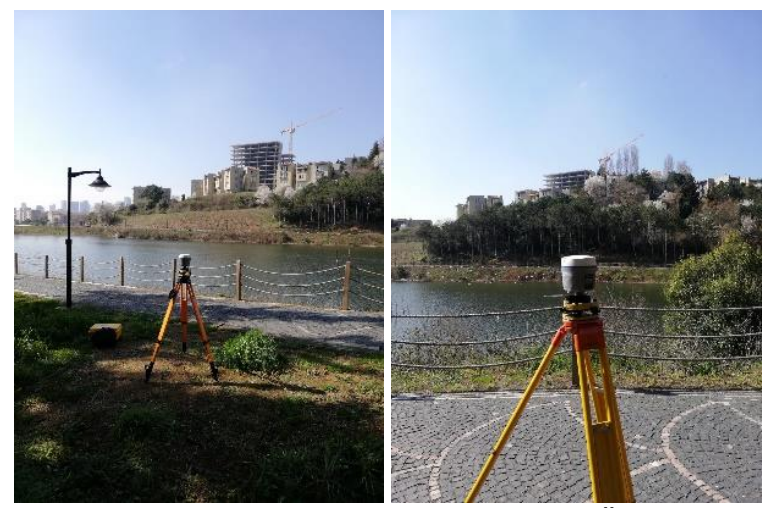

Şekil 3. Su Kıyısında Tesis Edilen Nokta Örnekleri

Yoğun Yerleșim Alanı: Kampüste yer alan yüksek katlı yapıların çevresindeki alanlar olarak tanımlanmıștır. Bu kapsamda 3 adet nokta tesis edilmiştir (Yoğun 1, Yoğun 2, Yoğun 3). Tesis edilen noktalardan bazı görüntüler Şekil 4'de verilmiştir.

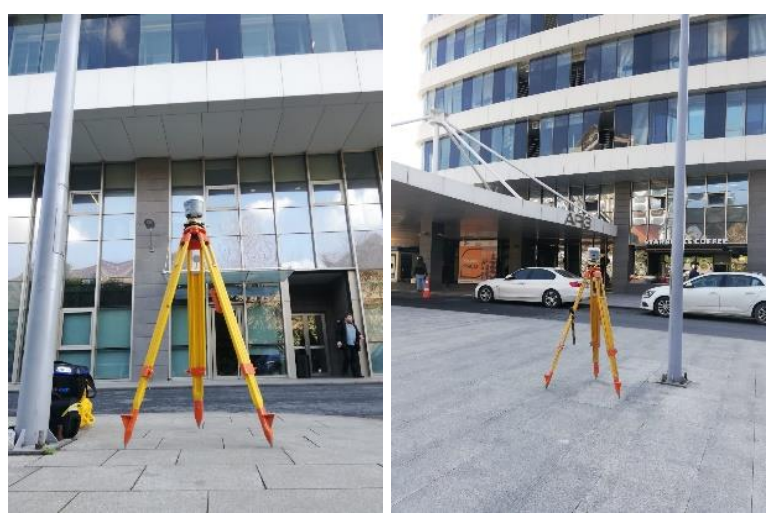

Şekil 4. Yoğun Yerleşim Alanında Tesis Edilen Nokta Örnekleri

Tesis edilen 12 noktada 90 ila 120 dakika arasında değişen sürelerde CHCNAV i80 multifrekans, multi-constellation GNSS alıcısı ile 9 ve 11 Mart 2020 tarihlerinde statik GNSS ölçmeleri gerçekleştirilmiştir. 10 derece uydu yükseklik açısı ve üzerinde görülebilen tüm uydu sistemlerine ait veriler 5 saniye kayıt aralığında toplanmıştır. Ölçmelerde kullanılan alıcıların temel bazı teknik özellikleri Tablo 1'de verilmiştir (Int Kyn. 6).

Tablo 1. Ölçmelerde Kullanılan CHCNAV i80 GNSS Alıcılarının Temel Bazı Özellikleri

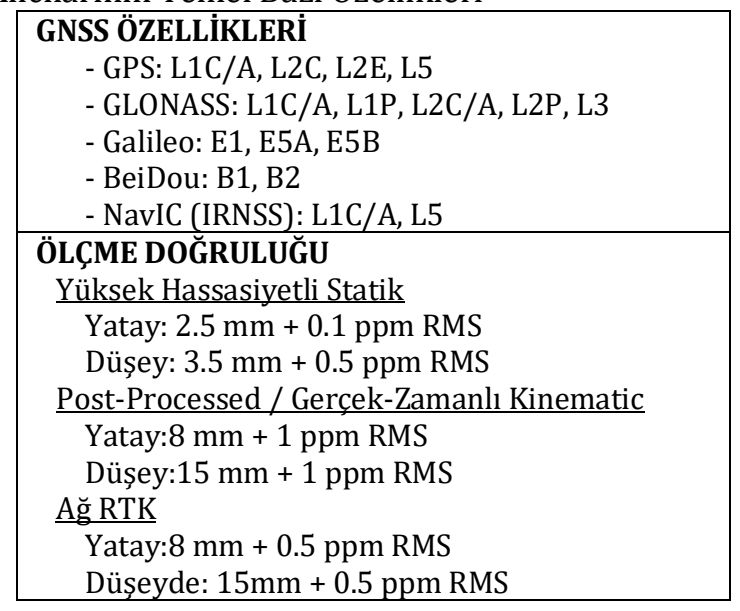

Ölçmeler süresince her bir noktada gözlemlenen GPS, GLONASS, Galileo ve BeiDou uydularının sayıları ile DOP (Dilution of PrecisionDuyarlılık Kaybı) değerleri Tablo 2'de özet olarak verilmiştir.

Tablo 2'de verilen değerlere bakıldığında, ölçme yapılan jeodezik noktalarda GPS (G) için en az 3 en fazla 9, ortalama 7; GLONASS (R) için en az 2 en fazla 8, ortalama 5; Galileo (E) için için en az 2 en fazla 8, ortalama 5; BeiDou (C) için en az 1 en fazla 10, ortalama 6 ve tümü için en az 12 en fazla 30 , ortalama 23 uydudan veri alındığı görülmektedir.

Diğer yandan hemen her noktada GPS'e ait ortalama GDOP değeri, diğer sistemlerin tümünden daha iyi bulunmuştur. Ancak tüm uyduların bir araya gelmesiyle oluşan 4'lü sistemde (GREC) GDOP değerleri en az 1 en fazla 2.9 ve ortalama olarak da 1.4 gibi oldukça iyi bir değere ulaşmıştır. Literatürde verilen farklı sınıflandırmalar olmakla birlikte, genel 
bir fikir vermesi açısından DOP değeri ile navigasyon performansı arasındaki ilişki Tablo 3'de verilmiştir (Liu et al., 2013).

Tablo 2. Ölçme Yapılan Noktalardaki Uydu Sayıları ve GDOP Değerleri

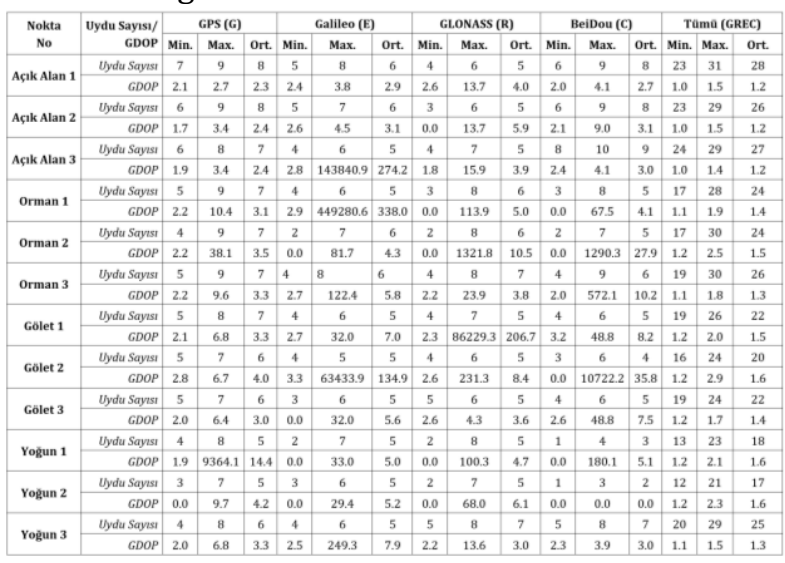

Tablo 3. DOP Değerleri ve Navigasyon Performansı İlişkisi

\begin{tabular}{cl}
\hline DOP Değeri & Değerlendirme \\
\hline$\leq 1$ & İdeal \\
$>1-2$ & Mükemmel \\
$>2-5$ & İyi \\
$>5-10$ & Orta Dereceli \\
$>10-20$ & Makul \\
$\geq 20$ & Zayıf \\
\hline
\end{tabular}

\subsection{Verilerin Değerlendirilmesi ve Sayısal Sonuçlar}

Farklı uydu sistemlerinin statik PPP çözümlerine olan etkisini araştırabilmek için $4^{\prime}$ lü uydu sistemlerinin tümünden toplanan veriler aşağıda verilen farklı senaryolarda değerlendirilmiștir:

Senaryo 1- Sadece GPS (G)

Senaryo 2-GPS+GLONASS (G+R)

Senaryo 3-GPS+Galileo (G+E)

Senaryo 4- GPS+BeiDou $(G+C)$

Senaryo 5- GPS+GLONASS+Galileo $(\mathrm{G}+\mathrm{R}+\mathrm{E})$

Senaryo 6- GPS+GLONASS+BeiDou $(\mathrm{G}+\mathrm{R}+\mathrm{C})$

Senaryo 7-GPS+Galileo+BeiDou $(\mathrm{G}+\mathrm{E}+\mathrm{C})$

Senaryo 8- GPS+GLONASS+Galileo+BeiDou $(\mathrm{G}+\mathrm{R}+\mathrm{E}+\mathrm{C})$

Günümüzde kullanılan online GNSS PPP değerlendirme yazılımlarının hemen tümünde çözümde kullanılmak istenilen uydu sistemleri seçilememekte, gönderilen RINEX dosyalarında hangi uydulara ait veriler varsa, onlar doğrudan değerlendirilmeye alınmaktadır. $\mathrm{Bu}$ yüzden ölçmelerde görünen tüm uydu sistemlerinden toplanan verilerin, yukarıdaki senaryolara göre değerlendirilebilmeleri için yeniden düzenlenmeleri gerekmiştir. Bunun içinde gfzrnx-RINEX GNSS Data Conversion and Manipulation Toolbox adl programdan yararlanılmıştır. gfzrnx 'GFZ Alman
Yerbilimleri Araştırma Merkezi (German Research Centre for Geosciences)'nin geliştirdiği bir yazılımdır. Bu yazılımla RINEX verilerinin;

$i$-) kontrol ve onarımı,

ii-) sürümler arasında dönüştürme,

iii-) veri bölme/birleştirme,

$i v^{-}$) veri düzenlenmesi (veri toplama aralığı, GNSS uydu ve gözlem tipi seçimi,

$v$-) veri karșlaștırması, gibi pek çok işlem yapılabilmektedir. Yazılım GPS, GLONASS, Galileo, BeiDou, IRNSS ve QZSS uydu sistemlerini desteklemektedir. Yazılım ile ilgili bilgiler Nischan (2016)'da detaylıca verilmektedir. $\mathrm{Bu}$ program aracıllğıyla tüm uydu sistemlerinden toplanan verileri içeren RINEX dosyaları, sadece her bir senaryoda belirtilen uydu sistemlerini içerecek şekilde alt gruplara ayrılarak, düzenlenmiştir. Böylelikle her nokta için alt RINEX dosyaları oluşturulmuştur. Örneğin sadece GPS olarak tanımlanan senaryoda sadece GPS uydularından alınan veriler bulunurken, GPS+Galileo olarak tanımlanan senaryoda ise GPS uyduları ile Galileo uyduları olacak şekilde düzenlenmiştir.

$\mathrm{Bu}$ işlemden sonra noktaların PPP yöntemi ile koordinatlarının belirlenmesi işlemine geçilmiştir. Bu kapsamda önceki bölümde incelenen web-tabanlı online GNSS PPP değerlendirme servisleri kullanılmıştır. Bunlar:

- Automatic Precise Positioning Service (APPS),

- Canadian Spatial Reference System-Precise Point Positioning (CSRS-PPP),

- magicGNSS-PPP,

- Trimble CenterPoint RTX Post-processing Service (Trimble RTX-PP) servisleridir.

Tablo 4'de, her bir servisin hangi uydu sistemini/sistemlerini kullanarak değerlendirme yaptığı verilmiştir. Tabloda yer alan \& işareti servisten cevap alındığı, $\otimes$ ifadesi ise servisten cevap alınamadığı anlamındandır.

Tesis edilen jeodezik noktalarda yapılan 4 'lü uydu sistemlerinin tümünün toplandığı "Ana Veri Setleri (RINEX Dosyalar)" ile, çalışma kapsamında belirlenen senaryolara göre olușturulan "Alt Veri Setleri (RINEX Dosyalar)" APPS, CSRS-PPP, magicGNSS ve Trimble CenterPoint RTX servislerine, statik PPP koordinatları hesaplanmak üzere gönderilmiștir. $\mathrm{Bu}$ sürece ait bilgiler, servislerin özelliklerinin ele alındığı Bölüm 3'de verildiği için, tekrarlanmamıştır. Her bir servise uygun RINEX formatındaki veriler gönderildikten kısa bir süre sonra sadece PPP koordinatları değil, değerlendirme işlemine ve yapılan hesaplara ait pek çok bilginin yer aldığı raporlar ve dosyalar e-posta aracilığıyla tarafımıza iletilmiştir. Çalışmada magicGNSS yazılımından 2 nokta kümesi için (Açık Alan ve Orman Alanı) çözüm alınamamıştır.

Her bir servisten, Senaryo 1-8 için elde edilen statik-PPP nokta koordinatlarının doğruluğunu belirleyebilmek için, tesis edilen jeodezik noktaların yüksek doğrulukla elde edilmiş bilinen koordinatlarına ihtiyaç bulunmaktadır. Bilindiği 
üzere günümüzde GNSS ile en yüksek doğrulukta konum, rölatif (göreli) yöntem ile belirlenmektedir. $\mathrm{Bu}$ çalışmada da noktaların koordinatlarının bu yöntemle belirlenmesinin uygun olacağ değerlendirilmiştir. Bunun için İTÜ Ayazağa Kampüsü İnşaat Fakültesi çatısında yer alan IGS noktalarından birisi olan ISTA istasyonu referans nokta olarak alınmış ve buna bağlı olarak klasik rölatif yöntemle noktaları koordinatları hesaplanmıştır. Hesaplarda Trimble Business Center (TBC) yazılımı kullanılmıştır. Yapılan hesaplamalar sonucunda her bir noktanin ITRF datumunda ve ölçme epoğundaki bilinen jeodezik koordinatları hesaplanmıştır. Yapılan hesaplar sonucunda noktaların yatay konum ve yükseklikleri sırasıyla 5 $\mathrm{mm}$ ve $11 \mathrm{~mm}$ 'lik bir ortalama hata ile hesaplanmıştır. Burada vurgulanması gereken bir durum, PPP koordinatı hangi uydu sistemi ile belirlendiyse, noktaların sabit koordinatları hesaplanırken de sadece o uydu sisteminin dikkate alındığıdır. Bununla birlikte rölatif yöntemden elde edilen bu koordinat setleri arasinda anlaml sayılmayacak düzeyde (birkaç mm mertebesinde) farklar bulunmuştur.

Son aşama olarak yukarıda bahsedilen tüm senaryolara göre hesaplanan statik PPP koordinatları rölatif yöntem ile belirlenmiș (bilinen) nokta koordinatları ile yatay konum (2D) ve elipsoidal yükseklik (h) bileşenleri için ayrı ayrı karşılaştırılmıștır. Elde edilen farklar Tablo 5'de ve Şekil 5’de verilmiştir.

Tablo 4. Çalışmada Kullanılan Servisler ve Değerlendirmeye Alınan Uydu Sistemleri

\begin{tabular}{|c|c|c|c|c|c|c|c|c|c|c|c|c|c|}
\hline \multirow{2}{*}{ Nokta No. } & \multirow{2}{*}{$\begin{array}{c}\text { APPS } \\
\mathbf{G}\end{array}$} & \multicolumn{2}{|c|}{ CSRS-PPP } & \multicolumn{2}{|c|}{ magicGNSS } & \multicolumn{8}{|c|}{ Trimble CenterPoint RTX-PP } \\
\hline & & G & $\mathbf{G}+\mathbf{R}$ & G & $\mathbf{G}+\mathbf{R}$ & G & $\mathbf{G}+\mathbf{R}$ & $\mathrm{G}+\mathrm{E}$ & $\mathbf{G}+\mathbf{C}$ & $G+R+E$ & $\mathrm{G}+\mathrm{R}+\mathrm{C}$ & $\mathrm{G}+\mathrm{E}+\mathrm{C}$ & $\mathrm{G}+\mathrm{R}+\mathrm{E}+\mathrm{C}$ \\
\hline Açık Alan 1 & 8 & ( ) & 8 & $\times$ & $\times$ & ( ) & ( & 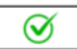 & 8 & Q & Q & ( & ( \\
\hline Açık Alan 2 & ( & ( & ( ) & $\times$ & (x) & (a) & (a) & (a) & ( ) & ( & (2) & (2) & (2) \\
\hline Açık Alan 3 & ( & ( ) & ( ) & 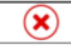 & (x) & (a) & (a) & (2) & ( ) & ( & 8 & (2) & ( \\
\hline Orman 1 & 8 & ( ) & ( & (x) & (x) & ( & 8 & 8 & ( ) & ( ) & ( ) & ( ) & ( ) \\
\hline Orman 2 & 8 & ( ) & 8 & (x) & (x) & ( ) & ( ) & () & (5) & 8 & () & ( ) & () \\
\hline Orman 3 & 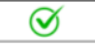 & ( & ( & $\boldsymbol{x}$ & (x) & ( ) & ( & (5) & ( & 8 & (5) & 8 & (5) \\
\hline Gölet 1 & ( ) & ( ) & ( & ( ) & ( ) & ( ) & ( ) & 8 & ( ) & ( ) & ( ) & ( ) & ( ) \\
\hline Gölet 2 & ( & ( & 8 & ( ) & ( & ( ) & (a) & ( & ( & 8 & ( ) & (5) & (5) \\
\hline Gölet 3 & ( & () & ( & () & 8 & ( ) & ( ) & () & 8 & 8 & () & () & () \\
\hline Yoğun 1 & 8 & ( ) & 8 & ( ) & ( ) & ( ) & 8 & ( ) & 8 & 8 & ( ) & 8 & ( ) \\
\hline Yoğun 2 & ( & ( ) & ( & (2) & () & (2) & (2) & (2) & ( ) & ( ) & (2) & ( ) & (2) \\
\hline Yoğun 3 & $\checkmark$ & ( ) & 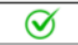 & $\checkmark$ & ( ) & ( & (5) & ( & ( & ( & ( ) & ( & () \\
\hline
\end{tabular}

Tablo 5. Jeodezik Noktaların Bilinen Koordinatlarıyla, Statik-PPP Koordinatları Arasındaki Farklar

\begin{tabular}{|c|c|c|c|c|c|c|c|c|c|c|}
\hline \multirow{3}{*}{ Nokta No. } & \multicolumn{2}{|c|}{ APPS } & \multicolumn{4}{|c|}{ CSRS-PPP } & \multicolumn{4}{|c|}{ magicGNSS } \\
\hline & $\mathbf{G}$ & $\mathbf{G}$ & $\mathbf{G}$ & $\mathbf{G}$ & $\mathbf{G}+\mathbf{R}$ & $\mathbf{G}+\mathbf{R}$ & G & G & $\mathbf{G}+\mathbf{R}$ & $\mathbf{G}+\mathbf{R}$ \\
\hline & $2 D(\mathrm{~cm})$ & $h(\mathrm{~cm})$ & 2D (cm) & $h(\mathrm{~cm})$ & 2D (cm) & $h(\mathrm{~cm})$ & 2D (cm) & $h(\mathbf{c m})$ & 2D (cm) & h (cm) \\
\hline Açık Alan 1 & 6.7 & -2.8 & 4.3 & 2.6 & 2.2 & 3.6 & $N / A$ & $N / A$ & $N / A$ & $N / A$ \\
\hline Açık Alan 2 & 3.8 & -11.9 & 5.0 & -19.0 & 2.5 & -11.2 & $N / A$ & $N / A$ & $N / A$ & $N / A$ \\
\hline Açık Alan 3 & 7.2 & -15.5 & 4.6 & -2.1 & 2.8 & 3.7 & $N / A$ & $N / A$ & $N / A$ & $N / A$ \\
\hline Orman 1 & 49.1 & 57.9 & 96.0 & -23.2 & 21.0 & -55.4 & $N / A$ & $N / A$ & $N / A$ & $N / A$ \\
\hline Orman 2 & 85.8 & 19.2 & 56.3 & 3.9 & 3.4 & -18.1 & $N / A$ & $N / A$ & $N / A$ & $N / A$ \\
\hline Orman 3 & 45.3 & 67.8 & 42.6 & 82.1 & 12.1 & 64.4 & $N / A$ & $N / A$ & $N / A$ & $N / A$ \\
\hline Gölet 1 & 35.3 & 16.9 & 27.0 & 25.7 & 6.0 & 18.1 & 22.4 & 25.1 & 6.2 & 16.7 \\
\hline Gölet 2 & 8.9 & 5.1 & 2.2 & 3.3 & 1.9 & 2.3 & 2.4 & 2.7 & 2.5 & 2.3 \\
\hline Gölet 3 & 6.8 & -4.3 & 9.2 & -7.6 & 1.7 & -1.5 & 12.7 & -0.2 & 8.9 & -2.0 \\
\hline Yoğun 1 & 27.3 & -10.3 & 5.6 & -18.3 & 7.1 & -0.6 & 20.1 & -5.8 & 16.2 & -6.0 \\
\hline Yoğun 2 & 4.3 & -2.4 & 14.3 & 1.6 & 6.8 & -2.3 & 12.9 & -7.3 & 6.4 & 3.4 \\
\hline Yoğun 3 & 7.1 & -4.0 & 8.6 & 7.9 & 0.9 & 11.2 & 2.1 & 2.2 & 5.5 & 3.0 \\
\hline
\end{tabular}


Tablo 5 (devamı). Jeodezik Noktaların Bilinen Koordinatlarıyla, Statik-PPP Koordinatları Arasındaki Farklar

\begin{tabular}{|c|c|c|c|c|c|c|c|c|c|c|c|c|c|c|c|c|}
\hline \multirow[b]{3}{*}{ Nokta No. } & \multicolumn{16}{|c|}{ Trimble CenterPoint RTX-PP } \\
\hline & G & G & $G+R$ & $\mathbf{G}+\mathbf{R}$ & $\mathrm{G}+\mathrm{E}$ & $\mathrm{G}+\mathrm{E}$ & $\mathrm{G}+\mathrm{C}$ & $\mathrm{G}+\mathrm{C}$ & $\mathrm{G}+\mathrm{R}+\mathrm{E}$ & $\mathrm{G}+\mathrm{R}+\mathrm{E}$ & $\mathrm{G}+\mathrm{R}+\mathrm{C}$ & $\mathrm{G}+\mathrm{R}+\mathrm{C}$ & $\mathrm{G}+\mathrm{E}+\mathrm{C}$ & $\mathrm{G}+\mathrm{E}+\mathrm{C}$ & $\mathrm{G}+\mathrm{R}+\mathrm{E}+\mathrm{C}$ & $\mathrm{G}+\mathrm{R}+\mathrm{E}+\mathrm{C}$ \\
\hline & $2 \mathrm{D}(\mathrm{cm})$ & $\mathrm{h}(\mathrm{cm})$ & $2 \mathrm{D}(\mathrm{cm})$ & $\mathrm{h}(\mathrm{cm})$ & $2 \mathrm{D}(\mathrm{cm})$ & $\mathrm{h}(\mathrm{cm})$ & $2 \mathrm{D}(\mathrm{cm})$ & h (cm) & $2 \mathrm{D}(\mathrm{cm})$ & $\mathrm{h}(\mathrm{cm})$ & $2 \mathrm{D}(\mathrm{cm})$ & $\mathrm{h}(\mathrm{cm})$ & $2 \mathrm{D}(\mathrm{cm})$ & $\mathrm{h}(\mathrm{cm})$ & 2D (cm) & $\mathrm{h}(\mathrm{cm})$ \\
\hline Açık Alan 1 & 5.5 & -2.3 & 2.2 & 4.3 & 1.2 & 5.5 & 3.0 & 3.2 & 2.2 & 4.1 & 2.8 & -4.9 & 2.1 & 5.9 & 2.0 & 18.2 \\
\hline Açık Alan 2 & 3.8 & 0.0 & 2.1 & -4.0 & 6.7 & 7.0 & 3.1 & -2.4 & 2.1 & -4.2 & 2.0 & 4.5 & 5.3 & 4.6 & 3.2 & 13.0 \\
\hline Açık Alan 3 & 4.9 & -5.5 & 1.8 & 5.0 & 2.1 & 2.1 & 6.9 & -10.6 & 1.8 & 4.8 & 2.5 & -3.1 & 3.1 & -0.6 & 2.5 & 14.8 \\
\hline Orman 1 & 24.4 & -22.2 & 9.9 & -24.1 & 15.2 & -45.5 & 23.9 & -23.5 & 4.0 & -40.9 & 10.4 & 24.4 & 15.3 & -45.7 & 3.7 & -32.7 \\
\hline Orman 2 & 150.0 & 41.5 & 8.4 & -27.1 & 29.2 & -15.8 & 149.5 & 41.1 & 8.2 & -26.9 & 8.9 & 27.4 & 30.5 & -14.3 & 9.1 & -13.9 \\
\hline Orman 3 & 85.5 & 66.2 & 43.6 & 51.1 & 50.8 & 56.3 & 85.4 & 66.9 & 41.3 & 53.0 & 47.5 & -53.6 & 50.7 & 56.5 & 45.7 & 68.6 \\
\hline Gölet 1 & 27.6 & 22.7 & 4.6 & 11.1 & 14.4 & 15.0 & 27.8 & 22.6 & 4.1 & 10.1 & 4.4 & -11.0 & 10.7 & 13.1 & 2.8 & 21.1 \\
\hline Gölet 2 & 1.9 & 0.7 & 1.7 & 0.5 & 2.2 & 1.9 & 1.8 & 0.6 & 2.0 & -0.7 & 2.0 & 0.8 & 2.4 & 1.4 & 2.0 & 12.3 \\
\hline Gölet 3 & 13.3 & -6.7 & 3.3 & -3.6 & 8.0 & -3.7 & 13.1 & -6.6 & 2.3 & -5.1 & 2.3 & 5.1 & 6.9 & 0.1 & 1.9 & 11.2 \\
\hline Yoğun 1 & 89.1 & 28.5 & 26.1 & -83.3 & 19.0 & -75.4 & 89.6 & 28.5 & 15.6 & -69.4 & 2.3 & 0.2 & 29.4 & -56.5 & 16.5 & -40.2 \\
\hline Yoğun 2 & 3.3 & 4.8 & 2.8 & -2.6 & 4.2 & 5.3 & 5.7 & 10.2 & 2.5 & 0.8 & 3.6 & -2.0 & 15.5 & 24.6 & 9.8 & 28.6 \\
\hline Yoğun 3 & 7.4 & 25.7 & 1.1 & 9.2 & 5.6 & 22.2 & 7.8 & 25.9 & 1.0 & 7.8 & 1.2 & -9.2 & 1.0 & 14.2 & 0.7 & 19.0 \\
\hline
\end{tabular}

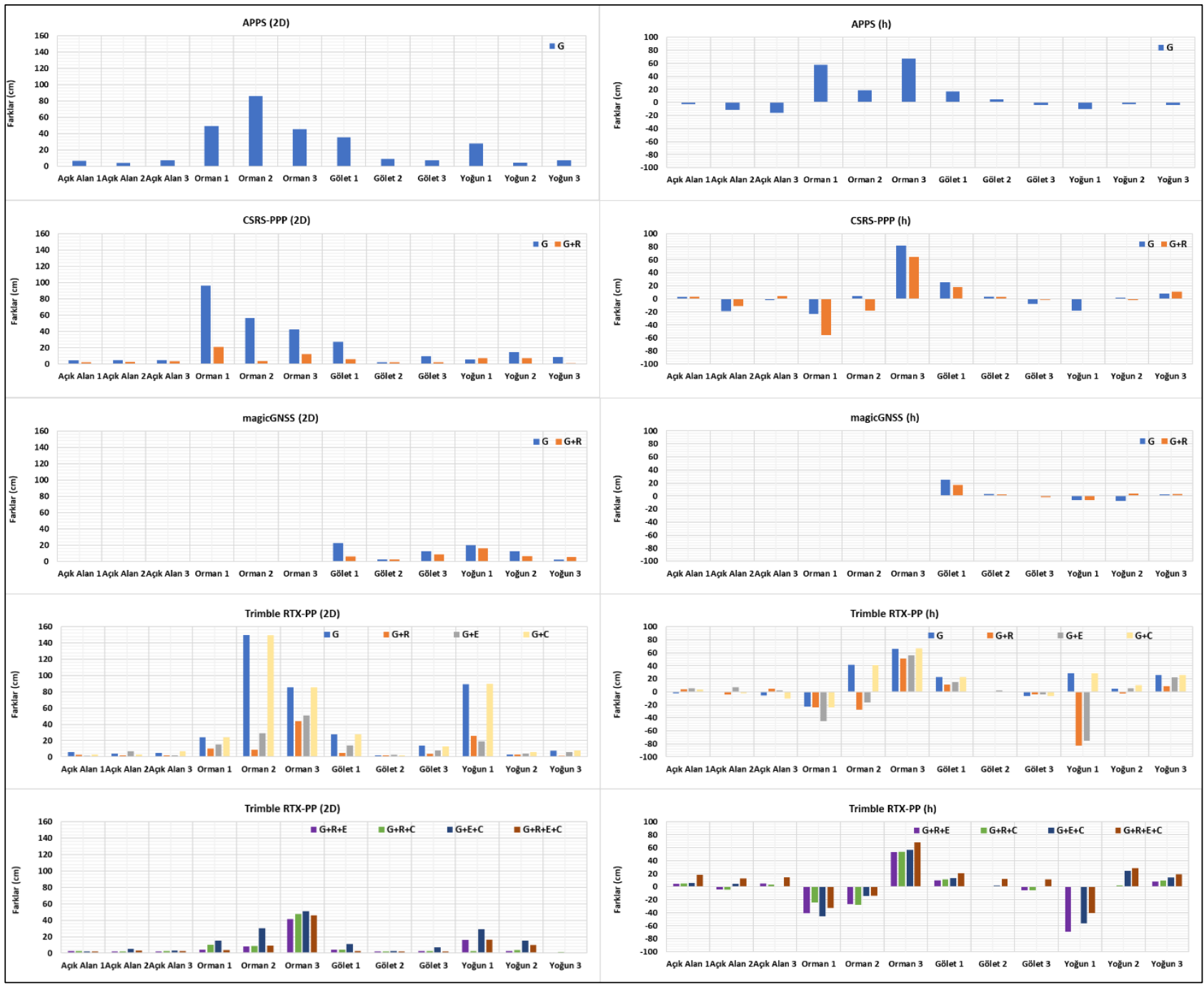

Șekil 5. Kullanılan Yazılımlara Göre Elde Edilen Farklar

\subsection{Bulgular ve Tartışma}

Ölçmelere ait GDOP değerleri ile gözlenen uydu sayllarının verildiği Tablo 2 incelendiğinde, GDOP değerlerinin ortalamalarının yalnızca GPS uydularına ait olan değerlerin, diğer uydu sistemleri ile karşılaștırıldığında en iyi olduğu; buna karşın bütün uydu sistemlerinin bir araya gelmesiyle oluşan dörtlü sistemde ise bu değerin tekli sistemlere göre çok daha iyi olduğu (GDOP=1.4) görülmektedir. Noktaların bir kısmının GNSS

ölçmeleri açısından kısıtlı yerlerde olduğu, yani etraflarının veri almaya engel yapay/doğal objelerle kapatılmış olduğu göz önüne alındığında, bu sonuç son derece önemlidir. Bu tür zorlu koşullarda çokluGNSS yapısı uydu sayısını artırmakta, buna bağlı olarak da uyduların dağılım geometrisini iyileştirerek konum doğruluğunun artmasına önemli katkı sağlamaktadır.

Tablo 5'de ve Șekil 5'de, en iyi koșullara sahip, genel olarak uydu gözlemi için bir kısıtın/engelin olmadığı "Açık Alan"larda yapılan ölçmelerden 
yalnızca GPS ölçülerinin değerlendirildiği sonuçlara bakıldığında, APPS, CSRS-PPP ve Trimble RTX-PP servislerinden yatay konumda $\mathrm{cm}^{\prime}$ ler mertebesinde, yükseklikte ise Trimble RTX-PP servisi ile yine $\mathrm{cm}$, diğer servislerde ise 2 dm'ye varan farklar elde edilmiştir. Diğer ölçme bölgelerinde ise, gerek yatay konum, gerekse de yükseklik bileşeninde dm'ler mertebesine varan farklar bulunmuştur.

GPS ve GLONASS uydularının birlikte değerlendirilmesi sonucunda "Açlk Alan" daki noktalar için elde edilen farkların, yalnızca GPS verilerinin değerlendirilmesine göre çok daha iyileștiği ve cm'ler mertebesine ulaştığı görülmüştür. Orman koşullarında yapılan ölçmelerin değerlendirilmesi sonucunda yatay konumda cm-dm mertebesinde farklar elde edilmişken, yükseklikte yarım metreye varan farklar elde edilmiștir. GPS+GLONASS konfigürasyonunun Gölet bölgesindeki 3 noktada da yatay konum doğruluğunu iyileştirdiği ( $\mathrm{cm}$ mertebesinde), yükseklikte de Gölet 1 noktası hariç birkaç cm'lik farkların elde edildiği görülmüştür. Son olarak Yoğun 1, 2 ve 3 noktalarının tümünde de iyileşme görülmekteyken, Yoğun 1 noktası hariç diğerlerinde $\mathrm{cm}-\mathrm{dm}$ mertebesinde farklar elde edilmiștir.

Çalışmada kullanılan APPS servisi yalnızca GPS verilerini değerlendirebilirken, CSRS-PPP ile magicGNSS'in ücretsiz hizmet veren servisi yalnızca GPS ve GPS+GLONASS uydularından alınan verileri birlikte değerlendirebilmektedir. Çalışmada kullanılan alıcılarla bu uyduların dışında Galileo ve BeiDou uydularından da gözlemler yapılmış olup, bu verilerin değerlendirilebilmesi sadece Trimble CenterPoint RTX-PP servisi ile mümkün olabilmiştir. RTX-PP servisi ile "Açık Alan" da yapılan ölçmelerin değerlendirilmesi sonucunda G, GR, GE, GC, GRE, GRC, GEC ve GREC uydu konfigürasyonlarında cm'ler mertebesinde yatay konum farklarına ulaşılmıştır. Bunların yükseklik bileşenleri içinse GREC konfigürasyonunda $\mathrm{dm}$, diğerlerinde ise $\mathrm{cm}$ mertebesinde fark elde edilmiştir. "Orman, Gölet ve Yoğun Alan" bölgelerinde birkaç istisna hariç olmak üzere, GR, GRE, GRC ve GREC konfigürasyonunda yatay konumda $\mathrm{cm}^{\prime}$ ler mertebesinde farklar elde edilirken, yükseklikte $\mathrm{cm}$ ila dm'ler arasında değișen farklara ulaşılmıştır.

Sonuçlar, değerlendirmede kullanılan servislere göre de yorumlanmıştır (Tablo 5 ve Şekil 5). Yalnızca GPS verilerini değerlendirmesi nedeniyle çokluGNSS olarak kabul edilemeyecek olan APPS servisinden elde edilen sonuçlara bakıldığında, ölçme koşullarının güçleştiği alanlarda noktaların yatay konum ve yüksekliklerinin bilinen koordinatlarla karşılaştırmasından elde edilen farkların arttığı, GNSS ölçme koşullarının zor olduğu bu tip bölgelerde yapılan konum belirleme çalışmalarının daha düşük doğrulukla sonuçlar ürettiği söylenebilmektedir.

CSRS-PPP servisinden elde edilen yatay konum ve yükseklik farklarına bakıldığında, açık alanlarda hem GPS, hem de GPS+GLONASS senaryolarından oldukça benzer ve iyi sonuçlar alındığı; buna karşın daha zor ölçme koşullarına sahip başta ormanlık alanlar olmak üzere diğerlerinde ise GPS+GLONASS kombinasyonunun yalnızca GPS'e göre sonuçları iyileştirdiği görülmüştür.

magicGNSS servisi ile hesaplanan PPP koordinatlarının karşılaştırma sonuçlarına bakıldığında, GPS+GLONASS konfigürasyonunun yalnızca GPS'e göre yatay konumda iyileşme sağladığı gözlenmektedir. Ancak Orman ve Açık Alanlarda yapılan ölçmeler için sonuç alınamamıştır.

Diğer bir web-tabanlı servis olan Trimble CenterPoint RTX-PP, çalışmada ele alınan 8 ayrı senaryonun tümüne de olumlu cevap vermiş, tüm kombinasyonlar için sonuç alınabilmiştir. Bu servis ile PP-AR yaklaşımı ile çözüm elde edildiği belirtilmiş olsa da, genel olarak bakıldığında float çözüm yapan diğer servislere göre daha iyi sonuçlar elde edilememiștir. Ancak servisin kendi içerisindeki karşılaştırmasına bakıldığında çoklu-GNSS'in hemen tüm senaryolarda önemli iyileşmeler sağladığı sonucuna ulaşılmıştır. Bu sonuçların içerisinde en anlamlı iyileşmeler ölçme koşullarının daha zor olduğu Orman ve Yoğun Yerleşim Alanlarında olmuştur. Örneğin Orman 2 noktasında sadece GPS ile elde edilen yatay konum farkı $150 \mathrm{~cm}$ iken diğer GNSS sistemlerinin kullanılması ile cm'ler mertebesine indiği gözlenmektedir. Yine yoğun şehir alanını temsil eden Yoğun 1 noktasında çoklu-GNSS çözümlerinin, tekli sisteme göre daha iyi sonuçlar verdiği açık bir şekilde gözlenmektedir.

Kullanılan servislere göre yapılan bu değerlendirmeler sonucunda, aşağıdaki genel sonuçlara ulaşılmıştır:

1-) Uydu gözlemleri için engellerin olmadığ gökyüzünün açı olduğu durumlarda tüm servislerden elde edilen farklar, hem yatay konum hem de yükseklik için santimetreler mertebesinde elde edilmiştir.

2-) Değerlendirme servislerinin içinde CSRSPPP servisinin GPS+GLONASS konfigürasyonunun genel olarak özellikle konum bileşeni için oldukça iyi sonuçlar verdiği görülmüştür.

3-) Servislerin hiç birisi tek başına tüm konfigürasyonlarda ve her türlü ölçme koşulunda en iyi sonucu verememiştir. Bir başka ifadeyle servislerin her birinden ölçme yapılan noktaya ve kullanılan uydu konfigürasyonuna göre değişen sonuçlar elde edilmiştir.

\section{SONUÇLAR}

$\mathrm{Bu}$ çalışmada farklı uydu sistemlerinin statik PPP nokta konum doğruluğuna olan etkisi incelenmiştir. Bu kapsamda farklı ölçme koşullarına sahip noktalarda yapılan ölçmelerden elde edilen GNSS verileri farklı senaryolar eşliğinde web-tabanlı online GNSS PPP değerlendirme servisleri ile değerlendirilmiş ve farklı GNSS uydu sistemlerinin kullanılmasının PPP konum doğruluğunu nasıl etkilediği ortaya konulmaya çalıșılmıştır.

Çalışmadan elde edilen sonuçlardan uygun ölçme koşullarına sahip (yapay/doğal engellerin 
olmadığı veya en az olduğu) ortamlarda yalnızca GPS uydu sistemi ile yapılan ölçmelerden $\mathrm{cm}$ mertebesinde doğrulukla konum belirlenebileceği, ancak daha zor ölçme koşullarına sahip bölgelerde tek GPS sistemi ile elde edilen doğruluğun düştüğü görülmüştür. Bu tür yerlerde çoklu-GNSS'in nokta konum doğruluğunu artırdığı sonucuna varılmıștır.

Çalışmada kullanılan web-tabanlı GNSS değerlendirme servislerinin konum belirleme performanslarının, ölçmelerin yapıldığı noktanın koşullarına ve değerlendirmede kullanılan uydu sistemlerine çok yakından bağlı olduğu görülmüștür. Diğer yandan aynı verilerden dört farklı servisin tümünden de farklı sonuçlar elde edilmiştir. Bunun en önemli nedeni servislerin arka planda kullandıkları yazılımların farklı olması, farklı stratejiler ile verileri değerlendirmeleridir. Buradan hareketle kullanıcıların tek bir servis ile yetinmeyip, oldukça kolay kullanıma sahip olan bu servislerin birden fazlası ile verilerini değerlendirmeleri, servislerce üretilen sonuç raporlarının titizlikle analiz edilerek yorumlamaları, dikkatle incelenmeleri önerilmektedir. Servislerden elde edilen koordinatlar arasındaki farkın ölçmelerden beklenen doğruluktan daha fazla olması durumunda bunun nedeni ortaya konulmaya çalșsılmal, hatta PPP yöntemine ek olarak SCOUT, OPUS, AUSPOS gibi rölatif yöntemle nokta koordinatlarını hesaplayan web-tabanlı online GNSS değerlendirme servislerinden de yararlanılmalıdır. Bu kapsamda mümkün olabildiğince sahada bazı kontrol mekanizmalarının kurulması, tekrarlı ölçmelerin yapılması vb gibi işlemlerle ölçmelerin doğruluğu ve güvenirliğinin artırılmasında da yarar bulunmaktadir. Zira servislerden elde edilen koordinatların derinlemesine analiz yapılmadan kullanılması durumu, özellikle zorlu koşullarda yapılan ölçmelerde kaba seviyede hatalara neden olabilecektir.

\section{TEŞEKKÜR}

Çalışma kapsamında sahada toplanan GNSS verilerimizin değerlendirilmesi imkanı sağladıkları için APPS, CSRS-PPP, magicGNSS ve Trimble CenterPoint RTX-PP online servislerine teșekkür ediyoruz.

\section{ARASTIRMACILARIN KATKI ORANI}

Ahmet Can Uçarlı: Literatür taraması, Veri toplama, Veri işleme, Araştırma, Makale yazma, Analiz ve yorum; Fatih Demir: Literatür taraması, Veri toplama, Veri işleme, Araştırma, Makale yazma, Analiz ve yorum; Serdar Erol: Denetim ve danışmanlık, Veri işleme, Makale yazma ve düzenleme, Analiz ve yorum, Eleştirel inceleme; Reha Metin Alkan: Fikir, Tasarım ve dizayn, Denetim ve danışmanlık, Makale yazma ve düzenleme, Analiz ve yorum, Eleștirel inceleme;

\section{ÇATIŞMA BEYANI}

Herhangi bir çıkar çatışması bulunmamaktadır.

\section{KAYNAKÇA}

Alkan, R.M., Ozulu, İ.M. ve İlçi, V. (2015). Deniz Uygulamalarında Hassas Nokta Konumlama Tekniğinin (PPP) Kullanılabilirliği Üzerine Bir Araştırma. Harita Dergisi, 154, 1-8.

Alkan, R.M., Ozulu, İ.M. ve İlçi, V. (2017). Klasik GNSS Veri Değerlendirme Yazılımlarına Alternatif Olarak Web-tabanlı Online Değerlendirme Servisleri. Afyon Kocatepe Üniversitesi Fen Bilimleri Dergisi, 17(2), 603-619.

Anderle, R.J. (1976). Satellite Doppler Positioning. Proceedings of the International Geodetic Symposium, Las Cruces, New Mexico, 12-14 October 1976, 47-75.

Bahadur, B. and Nohutcu, M. (2019). Comparative Analysis of MGEX Products for Post-Processing Multi-GNSS PPP. Measurement, 145, 361-369; https://doi.org/10.1016/j.measurement.2019.0 5.094 .

Bisnath, S., and Collins, P. (2012). Recent Developments in Precise Point Positioning. Geomatica, 66(2), 103-111; https://doi.org/10.5623/cig2012-023

Cai, C., Gao, Y., Pan, L., and Zhu, J. (2015). Precise Point Positioning with Quad-Constellations: GPS, BeiDou, GLONASS and Galileo. Advances in Space Research, 56(1), 133-143; https://doi.org/10.1016/j.asr.2015.04.001

Choy, S., Bisnath, S. and Rizos, C. (2017). Uncovering Common Misconceptions in GNSS Precise Point Positioning and its Future Prospect. GPS Solutions, 21(1), 13-22; https://doi.org/10.1007/s10291-016-0545-x.

Dawidowicz, K. (2020). Sub-hourly Precise Point Positioning Accuracy Analysis - Case Study For Selected ASG-EUPOS Stations. Survey Review, 52(373), 341-351; https://doi.org/10.1080/00396265.2019.15799 88.

Doucet, K., Herwig, M., Kipka, A., Kreikenbohm, P., Landau, H., Leandro, R., Moessmer, M., Pagels, C. (2012). Introducing Ambiguity Resolution in Web-hosted Global Multi-GNSS Precise Point Positioning with Trimble RTX-PP. Proceedings of the 25th International Technical Meeting of the Satellite Division of the Institute of Navigation (ION GNSS 2012), Nashville, TN, USA; 17-21 September 2012, 1115-1125.

Facio, Y. and Berber, M. (2020). Subsidence is Determined in the Heart of the Central Valley Using Post Processed Static and Precise Point Positioning Techniques. Journal of Applied Geodesy, 14(1); https://doi.org/10.1515/jag2019-0043.

Héroux, P. and Kouba, J. (2001). GPS Precise Point Positioning Using IGS Orbit Products. Physics and Chemistry of the Earth, Part A: Solid Earth and 
Geodesy, 26(6-8)

https://doi.org/10.1016/S1464-

573-578; 1895(01)00103-X.

Kahveci, M. ve Ylldız, F. (2012). GPS/GNSS Uydularla Konum Belirleme Sistemleri Teori ve Uygulama. Nobel Akademik Yayıncilık.

Kiliszek, D., and Kroszczyński, K. (2020). Performance of the Precise Point Positioning Method Along with the Development of GPS, GLONASS and Galileo Systems. Measurement, 164 , 108009; https://doi.org/10.1016/j.measurement.2020.1 08009 .

Liu, R., Guo, B., Zhang, A. and Yimwadsana, B. (2020). Research on GPS Precise Point Positioning Algorithm with a Sea Surface Height Constraint. Ocean Engineering, 197, 106826; https://doi.org/10.1016/j.oceaneng.2019.1068 26.

Liu, X., Wenhai, J., Bai, Y., and Fan, J. (2013). Global Coverage Performance Analysis Based on 4 BeiDou MEO Satellites. In: Sun J., Jiao W., Wu H., Shi C. (eds), China Satellite Navigation Conference (CSNC) 2013 Proceedings: BeiDou/GNSS Navigation Applications, Test \& Assessment Technology, User Terminal Technology, 319-330, Springer Science \& Business Media.

Nie, Z., Liu, F., and Gao, Y. (2020). Real-time Precise Point Positioning with a Low-cost Dualfrequency GNSS Device. GPS Solutions, 24(1), Article:9; https://doi.org/10.1007/s10291-0190922-3.

Nischan, T. (2016). GFZRNX-RINEX GNSS Data Conversion and Manipulation Toolbox (Version 1.05). GFZ Data Services. http://doi.org/10.5880/GFZ.1.1.2016.002.

Rizos, C., Janssen, V., Roberts, C. and Grinter, T. (2012). Precise Point Positioning: Is the Era of
Differential GNSS Positioning Drawing to an End? Proceeding of the FIG Working Week 2012, Rome, Italy, 6-10 May, paper 5909.

Wang, M. (2014). Ambiguity Resolution with Precise Point Positioning (Unpublished doctoral thesis). University of Calgary, Calgary, AB. doi:10.11575/PRISM/24782.

Zumberge, J. F., Heflin, M. B., Jefferson, D. C., Watkins, M. M., and Webb, F. H. (1997). Precise Point Positioning for the Efficient and Robust Analysis of GPS Data from Large Networks. Journal of Geophysical Research: Solid Earth, 102(B3), 50055017; https://doi.org/10.1029/96JB03860.

\section{Internet kaynakları}

Kyn. 1: CSNS-TARC Test and Assessment Research Center of China Satellite Navigation Office. http://www.csno-tarc.cn/en/index/index (11.08.2020).

Kyn. 2: The Automatic Precise Positioning Service of the Global Differential GPS System. https://apps.gdgps.net (11.08.2020).

Kyn. 3: Natural Resources Canada, Precise Point Positioning. https://webapp.geod.nrcan.gc.ca/geod/toolsoutils/ppp.php (11.08.2020).

Kyn. 4: magicGNSS Quality Data, Algorithms and Products for the GNSS User Comunity. https://magicgnss.gmv.com (11.08.2020).

Kyn. 5: The Trimble CenterPoint RTX PostProcessing Service. https://www.trimblertx.com (11.08.2020). Kyn. 6: CHCNAV i80 GNSS. https://www.chcnav.com/product-detail/i80gnss (11.08.2020). 